\title{
Democracia e participação no Brasil: descentralização e cidadania face ao capitalismo contemporâneo
}

\author{
Francisco Fonseca \\ Fundação Getúlio Vargas de São Paulo (FGV/SP)
}

Democracia e participação no Brasil: descentralização e cidadania face ao capitalismo contemporâneo Resumo: Este artigo analisa duas tradições opostas quanto aos conceitos de 'descentralização' e de 'poder local' (o pensamento social brasileiro e a matriz advinda de Tocqueville) em razão do papel concedido a tais conceitos pela Constituição de 1988, pois tidos como capazes de viabilizar a participação democrática após o fim da ditadura militar. Em contraste, analisa-se como o arranjo brasileiro pródemocracia e participação vem sendo reconfigurado pela terceira revolução industrial, que flexibiliza e precariza as relações econômicas e sociais em prol do capital. Especificamente, examina-se a resposta política (em sentido amplo) do Estado brasileiro - via políticas públicas de saúde, notadamente o SUS - a esse choque de forças contrárias. Observa-se também como aspectos federativos relacionados ao SUS permitem compreender a dinâmica da democracia, da participação e da cidadania (em várias dimensões) no Brasil.

Palavras-chave: democracia, participação, descentralização, capitalismo, cidadania.

\section{Democracy and Participation in Brazil: Decentralization and Citizenship in Contemporary Capitalism}

Abstract: This article analyzes two opposite traditions in relation to the concepts of "decentralization" and "local power" (Brazilian social thinking and the Tocqueville based matrix) due to the role given to these concepts by the Brazilian Constitution of 1988 . These concepts were considered capable of making viable democratic participation after the end of the military dictatorship. It also analyzes how the Brazilian pro-democracy arrangement and participation has been reconfigured by the third industrial revolution, which the economic and social relations that sustain capital more flexible and precarious. Specifically, it examines the political response (in a broad sense) of the Brazilian state - via public health policies, notably the Single Healthcare System (SUS) - to this clash of conflicting forces. It also observes how federative factors related to SUS allow understanding the dynamics of democracy, participation and citizenship (in various dimensions) in Brazil.

Key words: democracy, participation, decentralization, capitalism, citizenry.

Recebido em 16.04.2007. Aprovado em 05.07.2007. 


\section{Introdução}

A partir de 1988, opera-se no Brasil uma verdadeira revolução institucional resultante de lutas sociais e populares que se desenvolveram desde a década de 1970. Alguns temas-chave, entre inúmeros outros, a sintetizam: descentralização (sobretudo das políticas públicas), implicando um novo pacto federativo, donde se destacam os municípios como entes federativos; participação popular (canalizada pelos conselhos gestores e também por mecanismos de participação direta); e ascensão da cidadania em perspectiva universal (direitos coletivos, legitimação para punir crimes inafiançáveis contra grupos sociais específicos, códigos para segmentos vulneráveis da sociedade brasileira, e de direitos do consumidor).

Esse contexto histórico da redemocratização brasileira - iniciada em 1985, com a chamada 'Nova República', tendo culminado com a elaboração da Constituição em 1988 e com o retorno das eleições presidenciais diretas, em 1989 -, representou enorme ampliação de direitos. Tal ampliação, contudo, vem sendo contrastada pelo advento da terceira revolução industrial e da hegemonia das idéias liberalizantes: ambos esses movimentos sintetizam o capitalismo contemporâneo e incidem em forte perda de direitos, como veremos.

Dadas essas premissas, este artigo pretende refletir teoricamente sobre a questão da descentralização e do poder local, à luz da ampliação de direitos pós-1988. Paralelamente, pretende-se demonstrar os fatores contrastantes a esse movimento democratizante, marcado pela nova forma de produção e circulação dos bens e serviços provenientes da terceira revolução industrial que, por seu turno, é sustentada ideologicamente pelas idéias ultraliberais ${ }^{1}$. Para tanto, analisa-se o papel do Sistema Único de Saúde (SUS) como resposta - em várias dimensões e em termos de direitos sociais - aos impactos do capitalismo flexibilizado.

\section{Democracia e participação na lógica da des- centralização e do poder local: perspectivas teóricas}

Destacamos duas perspectivas teóricas relevantes para iluminar a discussão sobre o desenvolvimento da democracia e da participação pelo veio da descentralização e do poder local: o pensamento social brasileiro, que historicamente desconfiou do localismo, tendo em vista as raízes oligárquicas e patrimonialistas da formação social no país; e a experiência anglo-saxã, sintetizada conceitualmente por Tocqueville (1951), fortemente marcada pelo otimismo da comunidade local e também presente nos meios intelectuais nacionais.
Ambas as perspectivas, encarnadas em tradições sociais, são personificadas por atores sociais concretos e permeadas por pactos federativos que, no Brasil, além de terem no município um ente federado pós-1988, foram profundamente marcados pelos parcos períodos democráticos.

Dessa forma, a relação entre descentralização e pacto federativo, vista pelo ângulo dos poderes locais, adquire novos contornos, sobretudo conceituais, embora ancorados na realidade histórica. A comparação entre ambas as tradições traz elementos capazes de demarcar a democracia e a participação, sempre sob o ângulo do poder local na sociedade brasileira, sobretudo do século 19 (embora retomando períodos anteriores) aos dias de hoje.

Quanto ao pensamento social brasileiro, é notável sua desconfiança em relação ao poder local. A sociologia e a historiografia desenvolvidas por intelectuais como Oliveira Viana (1938), Victor Nunes Leal (1975) e Maria Isaura Pereira de Queiroz (1967, 1978), apenas para citar alguns, comprovam essa visão extremamente negativa quanto ao localismo e, conseqüentemente, à democracia e à participação popular. A base do argumento destes autores tem os seguintes componentes: no Brasil o universo local foi essencialmente dominado pelas oligarquias, pela escravidão e pelo grande latifúndio. Este teria essencialmente "simplificado as relações sociais" (LEAL, 1975) na medida em que a própria conformação de classes não expressava nem os interesses conflitantes - dado o ethos da "família ampliada", tema clássico de Gilberto Freyre (2003), cujos desdobramentos seriam justamente o patrimonialismo e a não constituição de uma esfera pública -, nem havia um Estado central interessado e capaz de combater as injustiças e os mandões locais, expressões do grande latifúndio. Toda uma cepa de autores desenvolveu essa matriz interpretativa, embora com prismas diversos, o que contribuiu para, já na Segunda República, acarretar a brutal centralização, agora por meio do Estado nacional, constituído após 1930. É importante ressaltar que, no Brasil, o Estado nacional se fez paralelamente à revolução industrial, capitaneado justamente pelo Estado. Mesmo a Constituição de 1946 manteve as estruturas criadas em 1930 que, por seu turno, foram derrogadas naquilo que tiveram de minimamente descentralizante e democrático, quando do golpe de 1964. Daí a importância do papel da democracia política à compreensão do pacto federativo no Brasil, isto é, sua quase inexistência foi crucial ao desenho institucional na história brasileira, relegando o município a participação e a cidadania aos 'coronéis' que, por isso, necessitavam ser controlados pelo poder central, segundo essa interpretação.

Em relação à tradição tocquevilleana, embasada no otimismo quanto ao poder local e ao espírito democrático da comunidade, esta contém a visão de que a 
colonização ocorrida nos EUA teria criado uma sociedade 'de baixo para cima', em que a 'comunidade' adquirira autonomia perante o Estado. Daí tal autonomia ter sido considerada fundamental tanto ao capitalismo empreendedor quanto à idéia de liberdade. A imagem de que a sociedade está 'de um lado' e o Estado 'de outro' implicou superestimar o papel das associações civis, despontando assim o conceito de sociedade civil em seu veio liberal, isto é, proveniente do liberalismo político. Contemporaneamente, o vasto e vago termo 'terceiro setor' parece ser uma continuação dessa visão liberal do mundo que, ao mesmo tempo em que divide rigorosamente Estado e sociedade, vê no primeiro um 'mal necessário' e no segundo um poder libertador. A lógica de que o poder local é necessariamente bom, controlável e equânime - de acordo com o espírito da comunidade - é, portanto, marcante. Do liberalismo político ao liberalismo econômico - notabilizado como neoliberalismo (ou ultraliberalismo, como preferimos) - a linha divisória por vezes tornouse tênue. Afinal, os liberais do século 20, por um lado, associaram capacidade empreendedora a tudo o que fosse iniciativa da comunidade e, por outro lado viram no papel minimizado do Estado o máximo desejável de regulação dos contratos e da garantia do "contrato social'. No mais, o indivíduo, sobretudo no âmbito local, deveria ser deixado só, dado que a sociedade seria um conjunto de 'átomos'.

Ambas as tradições, embora vigentes em períodos históricos e em lugares muito distintos, apresentam um quadro conceitual bastante significativo, pois contribuem para mapear pressupostos, diagnósticos e proposições. Todos esses elementos, articulados às vicissitudes do capitalismo vigente no Brasil ao longo do tempo e ao arcabouço institucional (democracia e suas modulações, e períodos ditatoriais), foram delimitados pelo contexto internacional, isto é: revoluções industriais, nacionalismo ou internacionalização, guerra ou paz, padrão de relação entre países centrais e periféricos, vetor da hegemonia, capitalismo versus socialismo, geopolítica, entre outros.

Portanto, a análise dessas tradições ajuda-nos a compreender o debate conceitual - por vezes imiscuído ao ideológico - acerca da democracia e da participação, tendo-se na descentralização e no poder local elementos centrais pós-1988, como veremos. Evidentemente que essas tradições são apenas algumas possibilidades analíticas, pois de forma alguma esgotam a compreensão da complexa temática em foco.

\section{A inédita ampliação de direitos na Consti- tuição de 1988}

Após uma longa história de autoritarismos - velados e/ou abertos - e de períodos democráticos parciais ou incompletos, a Constituição de 1988 (BRA-
SIL, 1999) foi profundamente inovadora, em diversas direções, permanecendo ainda hoje em processo de construção (vários artigos que necessitam de leis complementares, regulamentações, além da disjuntiva entre a lei e a realidade, entre inúmeras situações). As palavras-chave que sintetizam a Constituição, no espírito de uma verdadeira (re)fundação da República, são descentralização; participação popular; incorporação na vida política das associações civis; revalorização da ação política; e cidadania. Além dos movimentos sociais e populares, que tiveram papel decisivo na redemocratização, os conselhos gestores como espaço socioinstitucional inovador; a descentralização de recursos orçamentários, com vistas, sobretudo, a financiar políticas públicas sociais; as práticas do Orçamento Participativo; e os inúmeros arranjos político/federativos em âmbito local (consórcios os mais distintos, coordenação de políticas públicas, a questão das regiões metropolitanas, apenas para citar alguns exemplos, são amostras do conjunto de inovações existentes no Brasil pós-1988. Algumas delas foram expressas na Constituição e outras estimuladas por ela, isto é, decorrentes de seu ethos democrático e descentralizante.

Mas inúmeras outras inovações foram criadas, confluindo ou tornando-se suporte para a descentralização, pois a Constituição, segundo Souza e Lamounier (1990, p. 87 e 88, grifos dos autores):

Não abole nem restringe as tradicionais garantias e direitos individuais, mas estende-os a entidades coletivas. As maiores mudanças são as seguintes. Primeiro, o texto constitucional coloca os direitos e garantias individuais e coletivos bem no seu início, e não depois dos capítulos que tratam do Governo, como acontecia nos textos anteriores. Segundo, declara explicitamente (Artigo 5) que o princípio do tratamento igual perante a lei implica na ausência de discriminação de minorias, sejam elas mulheres, pretos ou quaisquer outras. A discriminação racial passou a ser vista como crime inafiançável. Terceiro, aos partidos políticos, aos sindicatos de trabalhadores e às associações voluntárias em geral, foi concedido o direito de se fazerem presentes na Justiça como pessoas coletivas, se os direitos dos seus representados estiverem sob ameaça iminente. Às entidades coletivas também foi concedido o novo 'mandato de injunção', que lhes permite mover ações judiciais sobre a constitucionalidade de leis e de atos administrativos (Artigo $5^{\circ}$., LXX, LXXI e XLII).

Como se observa, o avanço da democracia deuse em várias frentes, num movimento que procurou suplantar o passado escravista, elitista e autoritário da formação social brasileira. Novos direitos civis, políticos e sociais foram então incorporados à Constituição. Especificamente quanto ao sistema político, 
em que a participação política é central, as inovações são de grande magnitude, sobretudo:

No que diz respeito à democracia [...] a Assembléia Constituinte [...] Deu ao princípio participativo uma definição muito mais forte, colocando-o virtualmente em pé de igualdade com a democracia representativa. Os legisladores não apenas tornaram o princípio participativo operante nos níveis Legislativo e Judiciário, como também o adotaram como norma programática no Poder Executivo, em diversas situações administrativas específicas. [...] O Artigo 1 define o princípio da soberania popular como o exercício do poder através de representantes ou diretamente, como estabelecido na Constituição. Os elementos de soberania popular agora abrangem, além do voto, a iniciativa popular de legislação, o plebiscito, e o referendo popular (Artigo 11).

Quanto ao Poder Judiciário, o princípio participativo fica também fortalecido pela já mencionada legitimação de agentes coletivos.

No que se refere ao Poder Executivo, as novas nor mas são, de modo geral, menos imperativas, mas cumpre notar que as autoridades governamentais agora são compelidas a aconselhar-se com os cidadãos e a encorajá-los a participara numa série de área importantes. Programas de saúde, por exemplo, devem ser formulados e implementados consultando a comunidade (Artigo 203) (SOUZA; LAMOUNIER, 1990, p. 99, 100, grifos dos autores).

Essas passagens sintetizam a nova fase democrática que teve na Constituição de 1988 simultaneamente um ponto de culminância (em relação às lutas democráticas havidas na ditadura) e uma alavanca para a democratização futura da sociedade brasileira. Deve-se ressaltar, contudo, que, embora a carta constitucional seja um marco na vida de um país, não se pode adotar uma visão formalista, isto é, crer que o que está expresso nela seja vigente no mundo real. Dessa forma, êxitos e fracassos foram colhidos ao longo desse período, mas o fato marcante para a reflexão é a grande inovação havida, com conclusões distintas tanto ao nível empírico como conceitual.

Por fim, é importante ressaltar que, do ponto de vista socioeconômico, a Constituição também inovou ao inscrever direitos normalmente não claramente observáveis em textos constitucionais - motivo, aliás, de grande controvérsia até os dias de hoje -, tais como os relacionados à ampliação dos direitos vinculados ao trabalho:

O aspecto [...] [em que] aparece com maior nitidez a 'rejeição do passado' é no desejo dos legisladores de abolir desigualdades econômicas e sociais através da lei. A nova Constituição abriga extenso rol de novos direitos destinados a aumentar o quinhão econômico dos trabalhadores, sejam eles rurais e urbanos. Entre eles está a semana de 44 horas de trabalho em lugar da de 48; rigorosas penalidades por demissão sem motivo justo; licença-maternidade de 4 meses, sem prejuízo de vencimentos; aumento da retribuição salarial para horas-extras e férias; provisão de creches diurnas e escolas maternais para filhos de trabalhadores; licença-paternidade de 5 dias, sem prejuízo de vencimentos; e seguro-desemprego e aviso prévio proporcional ao tempo de serviço (Artigo7) (SOUZA; LAMOUNIER, 1990, p. 88- 89)².

Portanto, ao lado de avanços institucionais referentes à democratização do sistema político, que passou a incorporar as organizações da sociedade politicamente organizada, a garantir direitos coletivos e a tornar participativa a democracia representativa, entre outros avanços, houve um forte movimento rumo à tentativa de suplantar a enorme iniqüidade vigente no país, sobretudo relacionada aos direitos trabalhistas, entre outros direitos agora considerados sociais ${ }^{3}$. Embora jamais integralmente vigente, por diversas razões, o fato de tais direitos serem inscritos é o aspecto relevante para os fins deste trabalho, pois demonstra a criação de um novo marco jurídico às relações sociais no contexto de um novo arcabouço político referente ao regime democrático. Mas, paralelamente a esse movimento emancipador, alocado na superestrutura jurídico/política, a estrutura econômica do capitalismo contemporâneo atuava e atua cada vez mais no sentido inverso, isto é, volta-se à precarização e informalização das relações de trabalho, no contexto de robustas transformações na maneira de produzir. Afinal, o capitalismo 'flexível', que discutiremos abaixo, necessita cada vez mais de menos trabalhadores, em todos os setores da economia, para auferir lucros crescentes. Daí as infindáveis teses do 'fim do emprego'. Tudo isso responde pelo nome de terceira revolução industrial, cujos processos e efeitos são sentidos até os dias de hoje. É o que veremos agora, porém relacionado a outros períodos da história.

\section{Os efeitos da terceira revolução industrial na sociedade brasileira}

Como aludido, a compreensão do debate sobre democracia e participação ganha densidade se observarmos, como variável-chave, o tipo de capitalismo existente no Brasil ao longo de sua história, pois nos ajuda a conhecer suas permanências e rupturas nos dias de hoje. Em perspectiva histórica, isto é, observando-se do período colonial ao final do século 19, não apenas a base da economia brasileira fora fortemente regionalizada como o modelo fora forte- 
mente exportador. A colonização de cunho exploratório simplificou as relações sociais (no sentido de não permitir a existência de classes sociais autônomas) e fez da Coroa o verdadeiro poder central, mas com braços bem definidos nos extensos territórios brasileiros. Embora simplificadas as relações sociais, o papel do Brasil Colônia fora extremamente complexo, pois submetido à lógica global do capitalismo comercial: exploração de matérias-primas, comércio de escravos, compra de produtos elaborados na Europa, situação essa relativamente estável até o advento da República. Somente ao final do século 19 surgem forças industrializantes, afinal consolidadas na década de 1940, momento inicial que perdurou por cinco décadas e transformou o país em uma nação urbano-industrial, embora com desigualdades sociais e regionais presentes até hoje. A rapidez desse processo é gritante, aguçando velhas e criando novas contradições ao, agora, capitalismo industrial. O poder local (decorrência necessária ao debate sobre democracia e participação), em seu veio oligárquico, fora paulatinamente esvaziado com a ditadura de 1937 e com a atração dos empregos/direitos urbanos garantidos pela Era Vargas (tendo em vista que ao trabalhador rural não fora concedido tais direitos). A centralização, agora sob o predomínio do Estado nacional e do capitalismo industrial, fez-se de forma impressionante. Em outras palavras, o pêndulo teria girado do oligarquismo local (VIANA, 1938) ao centralismo republicano (mesmo que mancomunado com elites locais e regionais).

Portanto, é no período Vargas que se dá também o fenômeno da (célere) revolução industrial, o que significou o estabelecimento dos aludidos direitos políticos e sociais simultaneamente à constituição de um modelo urbano-industrial. Na verdade, a Era Vargas sintetiza incrivelmente uma tripla revolução: industrial; nacional (a formação de um Estado Nacional capaz de fazer-se presente nos rincões e universalizar-se); e social, em razão da criação de direitos, legislação e instituições sociais inéditas.

Ainda quanto ao regime político, uma nova realidade centralista (a partir de 1937) confinou política e institucionalmente os estados e municípios, o que, na prática, perdurou entre o regime militar e a redemocratização (1964-1988). A federação manteve esse nome apenas formalmente. Evidentemente os direitos sociais e políticos sofreram profundo retrocesso, pois democracia, participação, descentralização e cidadania foram conceitos excluídos do vocabulário autoritário.

É, portanto, somente em 1988, momento culminante da resistência democrática, que a situação de inverte, de forma inédita, pois a descentralização, agora sinônimo de participação e controle popular e social, faz-se presente. Ocorre, contudo, como aludimos, que ao lado dela a terceira revolução industrial dava e dá novos contornos ao capitalismo, pois impõe o 'modelo de acumulação flexível' (substituto do velho 'modelo fordista-keynesiano' vigente desde o após-guerra, e válido como vetor, embora com outros ingredientes, ao Brasil) como preponderante. Tal modelo pode ser sintetizado na extrema flexibilização das relações de produção - donde o capital financeiro ocupa papel central -, de trabalho e de consumo. Segundo Harvey ${ }^{4}$ (1992, p. 140-141),

A acumulação flexível [...] se apóia na flexibilidade dos processos de trabalho, dos mercados de trabalho, dos produtos e padrões de consumo. Caracteriza-se pelo surgimento de setores de produção inteiramente novos, novas maneiras de fornecimento de serviços financeiros, novos mercados e, sobretudo, taxas altamente intensificadas de inovação comercial, tecnológica e organizacional [...]. Esses poderes aumentados de flexibilidade e mobilidade permitem que os empregadores exerçam pressões mais fortes de controle do trabalho sobre uma força de trabalho de qualquer maneira enfraquecida por dois surtos selvagens de deflação [na década de 1970], força que viu o desemprego aumentar nos países capitalistas avançados [...] para níveis sem precedentes no pós-guerra. O trabalho organizado foi solapado pela reconstrução de focos de acumulação flexível em regiões que careciam de tradições industriais anteriores e pela reimportação para os centros mais antigos das normas e práticas estabelecidas nessas novas áreas. A acumulação flexível parece implicar níveis relativamente altos de desemprego 'estrutural' [...], rápida destruição e reconstrução de habilidades, ganhos modestos (quando há) de salários reais [...] e o retrocesso do poder sindical - uma das colunas políticas do regime fordista.

Como se vê, a terceira revolução industrial promove a extrema flexibilização dos fatores produtivos, tais como: o capital (ascensão de inéditos e preponderantes mercados financeiros); as formas de produção (just in time, subcontração em perspectiva internacional, obsolescência programada, entre outras); os padrões gerenciais (empresa enxuta, reengenharia, downsying); a força de trabalho (tendo em vista a precarização e as inúmeras formas temporárias e parciais de contratação, com impactos diretos na organização do trabalho, fragilizando-o); a circulação dos bens e serviços (em razão dos nichos de produção, desovados pela segmentação do consumo, em que o marketing e a propaganda ocupam papel central, reforçando além do mais a ideologia do descartável). Todo esse movimento opõe-se ao modelo fordista e keynesiano (marcado pela rigidez da utilização dos fatores produtivos) vigente nos países de capitalismo central e, embora com outros con- 
tornos, também está presente no Brasil e em vários países de capitalismo periférico. No caso brasileiro, a Era Vargas, como apontamos, teve inúmeros elementos marcados pelo vetor Estado (com alguns aspectos semelhantes à social democracia européia), isto é, o desenvolvimento e a criação de direitos sociais foram capitaneados pelo Estado.

Especificamente em relação à força de trabalho e aos direitos sociais ${ }^{5}$, todos os aspectos acima referidos estão presentes no Brasil, com o agravante de a economia brasileira ser historicamente dependente das esferas decisórias internacionais (dívida externa, nível do chamado 'risco país', investimentos estrangeiros, capital de curto prazo, tecnologia de ponta), além de extremamente oligopolizada. Em termos de distribuição de renda, também historicamente jamais a riqueza fora distribuída na proporção em que fora criada $^{6}$. Nesse cenário, o 'capitalismo desorganizado' e o 'capitalismo de cassino', para usar duas denominações conhecidas sobre o modelo flexível que vem surgindo da terceira revolução industrial, querem justamente expressar respectivamente a ausência de uma coordenação internacional dos capitais pelo Estado e a predominância, antes nunca vista, do capital financeiro sobre o produtivo, a ponto de diariamente circularem entre 1,5 e 3 trilhões de dólares em papéis, virtuais portanto. Como a quantidade de mão-de-obra é - nos três segmentos da economia -, como aludimos, cada vez mais diminuta, tanto o emprego formal como os direitos sociais são profundamente atingidos pela dinâmica do novo capitalismo contemporâneo. Não bastassem tais questões estruturais, a hegemonia das idéias ultraliberais - presente em governos, instituições multilaterais, universidades, na mídia, nos think-tanks, na agenda interna e externa, e no manejo político dos fatores produtivos - de fato impõe-se como irrecorrível, pois todos os espaços ideológicos foram paulatinamente ocupados. Embora sempre tenha havido e ainda haja resistências, é notório o enquadramento das discussões acerca do modelo de desenvolvimento e das políticas públicas pela ótica dos pressupostos ultraliberais.

Tudo isso contrasta com o vetor saído da Constituição de 1988. Afinal, o próprio momento de elaboração da Constituição - o declínio das teses heterodoxas, a decretação da moratória e a crise inflacionária e da dívida externa - já representou um contrafluxo importante aos desígnios dos constituintes. Portanto, de um lado há um capitalismo informalizante, precarizador das relações de trabalho, financeirizado e mundializado (e sem a existência de um contrapoder, dado o ocaso do socialismo) e de outro uma Constituição democrática, descentralizante, voltada à participação popular e à ampliação dos direitos de cidadania: esses movimentos representam um verdadeiro choque entre duas forças contrárias. Com isso, a "era dos direitos"
(BOBBIO, 1992) desfaz-se em boa medida no capitalismo flexibilizado. Como exemplo, o peso das contrapartidas exigidas pelo FMI e pelo Banco Mundial - financiadores robustos das sociedades periféricas, caso da brasileira -, além dos constrangimentos fiscais e da ausência de poupança interna, entre outros, são cruciais.

No que tange aos municípios - locus da participação popular e da democracia semidireta, tal como intentada pelos constituintes de 1988 -, o aumento exponencial em seu número, após 1988 (foram criados cerca de $40 \%$ a mais), com todo o aparato executivo/legislativo das grandes cidades, torna a existência da maior parte deles completamente dependente dos repasses federais, o chamado Fundo de Participação dos Municípios. Em outras palavras, novos poderes e institucionalidades federativos concedidos aos municípios tornam sua aplicabilidade extremamente dificultada por toda sorte de obstáculos e constrangimentos provenientes: do capitalismo mundializado, das entidades multilaterais (ambos direcionam o papel dos municípios), dos limites fiscais, e também institucionais, em razão da ausência de prerrogativas aos municípios por decisões interpostas pelo TSE e pelo Congresso Nacional. Tudo isso afeta, de diversas formas, a democracia e a participação no Brasil que, a despeito desse conjunto de constrangimentos, vêm avançando, embora num ritmo e numa dimensão aquém do esperado ${ }^{7}$.

Apesar de todas essas dificuldades, arranjos político-federativos, institucionais, societários, das políticas públicas e outros também, compõem o cenário da democracia brasileira, num incrível processo de inovação, ao mesmo tempo problemático e exitoso, mas voltado à busca de alternativas aos constrangimentos promovidos pela acumulação flexível e pela hegemonia ultraliberal.

Por fim, cabe ressaltar que a luta social em prol da democratização das sociedades (participação popular, informações transparentes, distribuição mais equiitativa dos recursos públicos e da riqueza criada, entre inúmeros outros aspectos) na atual quadra do capitalismo contemporâneo, dado que voltado à acumulação em bases antitéticas ao experimentado pelo pós-guerra, está em permanente processo. Nesse sentido, mesmo o Brasil tendo enveredado pela agenda ultraliberal desde 1990 com superávit primário e a precedência da responsabilidade fiscal, mas sem a contrapartida da responsabilidade social), há um conjunto de políticas públicas que vem avançando - no que tange à utilização dos recursos públicos em prol da distribuição da renda - que merece análise. Afinal, a democracia e a participação popular - temas eminentemente políticos - ampliam-se ao incorporar elementos substantivos à democratização: a distribuição da renda e a preocupação com as políticas sociais como extensão da democracia. Em outras pala- 
vras, a democracia, desde a década de 1930, e ainda mais após a redemocratização, torna-se polissêmica, pois não pode mais ser circunscrita à arena políticoinstitucional, embora continue a contemplá-la. A própria lógica dos conselhos gestores de políticas públicas confirma esta assertiva, dado que articula a gestão orçamentária de políticas específicas à participação popular, o que implica na fiscalização das verbas utilizadas. É o que veremos a seguir, de forma breve.

\section{Democracia, participação e cidadania nas polí- ticas públicas}

A Constituição de 1988, ao ampliar direitos, constitucionalizou verbas (conhecidas como 'verbas carimbadas') em áreas essenciais, tais como educação e saúde, e paulatinamente vem promovendo contornos sistêmicos às principais políticas públicas, casos das aludidas áreas de saúde (SUS) e da educação (Fundo de Manutenção e Desenvolvimento da Educação Básica - FUNDEB), mas também da assistência social (Sistema Único de Assistência Social - SUAS) e da segurança (Sistema Único de Segurança Pública - SUSP). Em razão de espaço, utilizaremos apenas o exemplo do SUS, tendo em vista ter sido pioneiro e possivelmente o mais bem sucedido aos propósitos a que se propõe.

A lógica dos sistemas significa que as "verbas carimbadas' inscrevem no orçamento a obrigatoriedade de financiar áreas sociais específicas. A idéia de um sistema único implica que a União e todos os estados e municípios (por meio de competências e distinções) devem ter como parâmetro a Constituição e um conjunto de normas infraconstitucionais no que tange à utilização de recursos públicos nas áreas aludidas. Note-se que essa constitucionalização significa a garantia de que, independentemente de quem esteja no poder, serão utilizados percentuais pré-fixados do orçamento quanto a áreas básicas. Isso é extremamente positivo tendo em vista a histórica apropriação do Estado pelas mais variadas elites. Contudo, o desejo soberano do cidadão - no momento do voto, constituindo-se em maioria - representa um menor peso quanto à alocação do orçamento. Em outras palavras, há uma tensão entre esses dois argumentos legítimos. Mas dadas as características político-sociais do país - sua formação histórica colonial, latifundiária e escravista, o papel da histórica e profunda desigualdade social, a formação autoritária do Estado e a tutela das modernas classes sociais no pós-1930, entre outras -, considera-se preferível a constitucionalização das verbas, como de política de Estado, e não de governo, o que garantiria sua perenidade.

Especificamente quanto ao SUS, seus principais marcos institucionais são: a Constituição Federal de 1988 (BRASIL, 1999, artigos 196 a 200); a Emenda
29; a Regulamentação da PEC 29; a Lei 8080; a Lei 8142; a Norma Operacional da Assistência à Saúde NOAS/SUS 2002; a Norma Operacional Básica NOB/SUS 01/96 (BRASIL, 2007). Note que o processo de regulamentação do sistema de saúde obtém significativo avanço com a promulgação da Lei Orgânica de Saúde, Lei n. 8.080, de setembro de 1990, pois:

a) define o SUS como um conjunto de ações e serviços de saúde prestados por órgãos e instituições públicas em todos os níveis de governo - com caráter complementar para a iniciativa privada;

b) disciplina a atuação permanente da análise das condições de saúde e de seus determinantes;

c) atribui responsabilidades pela formulação das políticas de saúde e de assistência;

d) determina seus princípios e diretrizes, ressaltando-se, entre outros, a universalidade de acesso, a integralidade da assistência, a eqüidade, a participação da comunidade, a descentralização político-administrativa com direção única em cada esfera de governo e articulação dos recursos financeiros, tecnológicos, materiais e recursos humanos de todos os níveis (esses aspectos são os mais marcantes para a demonstração da importância do SUS);

e) define as atribuições e competências de cada nível de governo.

No que tange aos municípios, define o gerenciamento e a execução dos serviços públicos de saúde ao criar sistemas locais. Quanto aos estados, baliza a promoção e descentralização dos serviços e ações de saúde, o que implica o apoio técnico e financeiro aos municípios. Apenas supletivamente os estados executarão ações e serviços de saúde. Suas atribuições referem-se, principalmente, ao acompanhamento, ao controle e à avaliação das redes hierarquizadas do SUS, bem como a gestão dos sistemas públicos de alta complexidade, de referência regional e estadual. Também em 1990 foi sancionada a Lei n. 8.142 que dispõe sobre a participação da comunidade na gestão do SUS e sobre as transferências intragovernamentais de recursos financeiros na área da saúde. Como dissemos, a participação social - que pode se desdobrar em controle social - adquire contornos institucionais de forma clara após a democratização.

Já a Norma Operacional Básica - NOB/SUS 93 procurou disciplinar a construção do Sistema Único de Saúde. Para Arretche (1996), esta norma fortalece a relação entre governo federal e municípios e supõe graus distintos de responsabilidade sobre a gestão dos serviços. A NOB em foco estabeleceu que a habilitação ao SUS somente pode ocorrer por solicitação municipal. Cumpridos os requisitos básicos e aprovada a adesão ao processo de municipalização das polí- 
ticas de saúde, as cidades passam a ter inúmeras atribuições na gestão do sistema local de saúde, que diferem de acordo com o modelo de adesão.

Em termos históricos, desde 1998 o sistema de saúde foi submetido a uma profunda reestruturação com a entrada em vigor de uma nova regulamentação, a Norma Operacional Básica do Sistema Único de Saúde/1996, a NOB-96. Sua diretriz foi sintetizada no lema "Gestão plena com responsabilidade pela saúde do cidadão". Os princípios se mantiveram, isto é, a universalidade, a eqüidade, a integralidade da assistência e a responsabilização do Estado pela saúde dos cidadãos, mas com as seguintes alterações:

a) radical avanço na responsabilidade dos municípios pela gestão da política de saúde e mais ainda em sua responsabilização pela gestão da política de saúde com a criação do SUS municipal, que consiste em subsistemas, um para cada município, que deve responder pela totalidade das ações e de serviços de atenção à saúde no âmbito do SUS;

b) redefinição do papel dos estados e da União na gestão do Sistema. Determina-se que estes são sempre co-responsáveis pelo SUS em suas respectivas competências ou na ausência da função municipal;

c) redefinição dos modelos de gestão municipal da saúde. Essa nova normatização reviu os modelos então vigentes e criou duas novas categorias distintas de gestão às quais os municípios podem se habilitar: a Gestão Plena da Atenção Básica e a Gestão Plena do Sistema Municipal (BARRETO JUNIOR; SILVA, 2004).

Em relação ao arcabouço institucional de gestão do SUS, "a União ficou encarregada do financiamen to e formulação da política nacional de saúde, bem como da coordenação das ações intergovernamentais. O Governo Federal - isto é, o Ministério da Saúde - tem autoridade para tomar as decisões mais importantes nesta política setorial" (ARRETCHE, 2004, p. 22). A principal arena de formulação da política nacional tem sido o próprio poder Executivo e apenas marginalmente o Congresso Nacional. Os estados e municípios vêm sendo, dessa forma, enquadrados nessa nova moldura ${ }^{8}$, respondendo portanto aos novos desafios colocados pela terceira revolução industrial: empobrecimento das classes médias, o que leva à maior procura pelo sistema pública de saúde; informalidade e preca- riedade das relações de trabalho, o que implica um maior número de acidentes no exercício do trabalho (quesito em que o Brasil é campeão), demandando ainda mais ao sistema público; crise do sistema privado de saúde, por motivos diversos, sobrecarregando sobremaneira setor público; entre outros aspectos.

Quanto aos governos locais - locus da democracia participativa -, tornaram-se agentes de implementação das políticas formuladas pelo Ministério da Saúde. Em outras palavras, o governo federal dispõe de recursos político/institucionais para influenciar os governos locais, afetando sua agenda. "A participação de estados e municípios no processo de formulação da política de saúde, por sua vez, está institucionalizada por meio de Conselhos com representação de estados e municípios" (ARRETCHE, 2004, p. 23). A NOB 93 institucionalizou a Comissão Intergestores Tripartite e as comissões Intergestores Bipartite que, juntamente com o Conselho Nacional de Saúde, são fóruns de pactuação da política nacional de saúde. Tais fóruns são mecanismos de discussão, e de poder, entre as unidades da federação. "A institucionalização desses espaços suprimiu do Ministério da Saúde a possibilidade de estabelecer unilateralmente as regras de funcionamento do SUS. Tais Conselhos funcionam como um mecanismo de contrapeso à concentração de autoridade conferida ao Executivo Federal" (ARRETCHE, 2004, p. 23). Não se deve confundi-los, contudo, com os Conselhos populares. Estes, quando funcionam, representam importantes espaços de participação popular, superando assim a lógica estritamente institucional da democracia parlamentar.

Como se observa, a lógica do SUS - assim como do Fundeb, do SUAS e do SUSP, embora haja diferenças quanto à origem dos recursos e às contrapartidas entre os três níveis da federação - sintetiza o sentido expandido de democracia, como afirmamos, pois articula a política social: à lógica do sistema, com predominância federal na articulação das políticas com os entes federados; ao papel específico do município; à constitucionalização das verbas; e à participação popular. Em outras palavras, elementos federativos - institucionais, portanto - somam-se à participação política, sobretudo popular, via conselhos gestores, e à ampliação dos direitos de cidadania, respondendo assim, de certa forma, aos desafios do capitalismo contemporâneo. Denotase aqui a junção - teoricamente relevante - entre 
institucionalização de procedimentos referentes às políticas públicas e participação popular, por sua vez também institucionalizada enquanto locus de atuação'.

É importante ressaltar que esse breve histórico e análise da dinâmica do SUS sintetiza as seguintes questões: a) a resposta do Estado brasileiro, no setor da saúde, quanto à demanda pela ampliação e organicidade das áreas sociais, sobretudo saúde e educação; b) a relação entre esta ampliação - como marco da democracia social - e a lógica federativa do sistema político brasileiro, o que, aliás, diz muito quanto à democracia político/institucional; $\mathrm{c}$ ) o papel da participação popular na gestão da saúde, o que implica, ao menos de forma potencial, a tentativa de levar a cabo a democracia participativa no país pós1988; d) os impactos da terceira revolução industrial, por meio do modelo de acumulação flexível, quanto ao aumento da demanda pelos serviços públicos de saúde; e e) a importância de analisarmos todos esses aspectos, sobretudo as vicissitudes empíricas da construção do SUS como uma combinação de demandas históricas com novos arranjos políticos, federativos, institucionais e sociais.

\section{Considerações finais}

Tendo em vista o debate sobre 'descentralização' e 'poder local' no Brasil, que se institucionalizou como canais de participação na Constituição de 1988, observamos o contramovimento da acumulação flexível advindo da terceira revolução industrial. Em tal contramovimento, a força de trabalho experimenta retrocessos quanto aos direitos do trabalhador em várias dimensões: ocupações parciais, temporárias e, sobretudo, precárias e informais, em contraste ao emprego formal construído desde a década de 1930; direitos sociais sintetizados no welfare state (em suas várias gradações, dependendo do país) em franco retrocesso e focalização (contraface da universalização); predominância da lógica fiscal sobre a social. Tudo isso é sintetizado na hegemonia internacional das idéias ultraliberais, personificadas na agenda mundial (que se aplicaram sobretudo aos países periféricos), na mídia, nos departamentos de economia de determinadas universidades brasileiras e internacionais, e sobretudo nos financiamentos do Fundo Monetário Internacional e do Banco Mundial, além dos outros fóruns internacionais, tais como a Organização Mundial do Comércio e as infinitas rodadas de liberalização do comércio mundial.

Embora sejam dois movimentos contrários (o ethos de 1988 e os efeitos da acumulação flexível), há respostas interessantes e alternativas no Brasil: a lógica dos sistemas (sintetizada no SUS, mas válida para outras políticas públicas) de certa forma consegue deter, ao menos parcialmente, o gigantes- co movimento de exclusão de direitos. Dado que a estrutura econômica do capitalismo contemporâneo é profundamente precarizadora, poupando significativamente a contratação de trabalhadores, ao Estado parece caber um papel ainda mais atuante, em termos sociais, do que teve no passado recente. Como sua capacidade para fazer grandes investimentos é pequena, notadamente aos Estados periféricos, caso do Brasil, a constitucionalização de recursos, associada à gestão popular (conselhos gestores) e à execução municipal das políticas de saúde, é uma forma inovadora capaz de responder politicamente às transformações do capitalismo. Mesmo que seus efeitos sejam parciais, trata-se de uma importante resposta - culminantes das lutas populares desde a década de 1970 - da democracia e da participação face aos impactos do capitalismo contemporâneo.

A articulação de diversas variáveis, tais como o papel dos municípios, - no contexto federativo da democracia político/institucional, o que implica articulação de níveis de governo e de mecanismos de políticas públicas; a resposta do Estado brasileiro aos efeitos da terceira revolução industrial, por meio de políticas públicas; o papel da participação popular (via conselhos gestores), que reconfigura a 'democracia parlamentar'; e a reinterpretação da cidadania, tendo em vista seus múltiplos significados, isto é, como direitos sociais, como direito à participação (política) da gestão, como universalização de direitos básicos, e como aproximação ao nível local do exercício do direito à saúde e educação. Todos esses aspectos condensam-se tendo em vista os efeitos da terceira revolução industrial e as respostas do Estado brasileiro perante eles, ao lado das históricas lutas pela democratização da sociedade brasileira (em várias dimensões), compondo um quadro complexo, porém claro, sobre o grande 'laboratório' político/social que é o Brasil do pós-1988 aos dias de hoje.

\section{Referências}

ARRETCHE, M. Mitos da descentralização: maior democracia e eficiência nas políticas públicas? Revista Brasileira de Ciências Sociais, São Paulo: ANPOCS, ano 11, n. 31, p. 44-66, 1996.

Federalismo e políticas sociais no Brasil: problemas de coordenação e autonomia. São Paulo em Perspectiva, São Paulo: Fundação SEADE, v. 18, n. 2, p.1726, abr./jun. 2004.

BARRETO JUNIOR, I. F.; SILVA, Z. P. Reforma do Sistema de Saúde e as novas atribuições do gestor estadual. São Paulo em Perspectiva. São Paulo: Fundação SEADE, v. 18, n. 3, p. 47-56, jul./set. 2004. 
BOBBIO, N. Era dos direitos. Rio de Janeiro: Campus, 1992.

BRASIL. Constituição da República Federativa do Brasil. Promulgada em 5 out. 1988. São Paulo: Atlas, 1999.

. Ministério da Saúde. Legislação. Normas Básicas do SUS. Disponível em: < http://portal.saude.gov.br/portal/ saude/>. Acesso em: jan. 2007.

FERREIRA, S. Federalismo fiscal, municípios: despesa com saúde e transferências federais. Informe-se, BNDES, n. 38, 2002. Disponível em:<http://www.federativo.bndes.gov.br/ clientes/federativo/resposta aut.asp?texaut=Ferreira $>$. Acesso em: jan. 2007.

FONSECA, F. O consenso forjado - a grande imprensa e a formação da agenda ultraliberal no Brasil. São Paulo: HUCITEC, 2005.

FREYRE, G. Casa grande \& senzala: formação da família brasileira sob o regime de economia patriarcal. São Paulo: Global, 2003.

GESTÃO PÚBLICA E CIDADANIA. Iniciativa da Fundação Getúlio Vargas e Fundação Ford com apoio do BNDES. Programa Gestão Pública e Cidadania. Disponível em: 〈http://inovando.fgvsp.br/>. Acesso em: jan. 2007.

HARVEY, D. Condição pós-moderna. Rio de Janeiro: Loyola, 1992.

IBGE - Instituto Brasileiro de Geografia e Estatísitca. Estatísticas do século XX. Disponível em <http:// www.ibge.gov.br/seculoxx/default.shtm>. Acesso em: fev. 2007.

LEAL, V. N. Coronelismo, enxada e voto. São Paulo: AlfaOmega, 1975.

MARQUES, E. C.; ARRETCHE, M. Condicionantes locais da descentralização das políticas de saúde. Cadernos do CRH, Salvador, v. 39, p. 55-81, 2003.

MEDICI, A. El desafío de la descentralización: financiamiento público de la salud en Brasil. BID, Washington DC, 2002.

QUEIROZ, M. I. P. de. Bairros rurais paulistas: estudo sociológico. Revista do Museu Paulista, São Paulo, n. 17, p. 63-206, 1967.

. Cultura, sociedade rural, sociedade urbana no Brasil. São Paulo: EDUSP, 1978.

SADER, Eder. Quando os novos personagens entram em cena: experiências, falas e lutas dos trabalhadores da Grande São Paulo (1970-80). Rio de Janeiro: Paz e Terra, 1988.

SANTOS JR. O. A. dos. Democracia e governo localdilemas da reforma municipal no Brasil. Rio de Janeiro: Revan, 2001.

SINGER, P. ACidadania para todos. In: PINSKY, J.; PINSKY, C. (Org.). História da cidadania. São Paulo: Contexto, 2003. p. 191-263.

SOUZA, A.; LAMOUNIER, B. (Org.). De Geisel a Collor: o balanço da transição. São Paulo: Sumaré, 1990.

TOCQUEVILLE, A. De la démocratie en Amérique. Paris: Calmann Lévy, 1951.

VIANA, O. Populações meridionais do Brasil - história, organização e psycologia. São Paulo: Companhia Editora Nacional, 1938.

\section{Notas}

1 Denominamos 'ultraliberal' o movimento conhecido como neoliberal em razão da radicalidade tanto de seus diagnósticos como de suas proposições. Não bastasse isso, 'neo' indica 'novo',mas as atuaisidéias liberais remontam ao final do século 19, tendo se desenvolvido no século 20. Oneoliberalismo fora novo em relação ao liberalismo vigente até o século 19 , tendo em vistaque seus inimigos eram outros: não mais as monarquias absolutistas e as corporações de ofício, e sim o socialismo, a social democracia, os sindicatos, entre outros.

2 A grande mídia como ator político/ideológicoe representante de setores do capital e das classes médias postou-se de forma extremamente contrária a esse conjunto de novos direitos sociais. Apesar do poder que os jornais possuem em relação aos 'formadores de opinião', os constituintes, lastreados nos movimentos sociais e populares e num intenso clima de mobilização popular, inscreveram tais artigos na Constituição. Para uma análise desta mobilização, em relação à posição da grande imprensa, ver Fonseca (2005).

3 Éimportanteressaltarquejustamentenoanoemqueforainstalada aAssembléia Constituinte o Brasil declarou moratória da dívida externa. Assim, houve uma contradição interna no sentido de demandas pela ampliação de direitos e de gastos sociais e o apertofiscal eorçamentárioexistente, cujamoratória veioasomarse como um constrangimento produtor de inúmeros impactos. O fato de, ainda assim, os constituintes terem ampliado direitos e gastos mostra o quão importante fora aquele momento e o quão significativa é a atual Constituição.

4 É importante ressaltar que a perspectiva deste autor, tal como a nossa, tem como pressuposto a chamada Escola da Regulação. 
5 Para uma importante e detalhada relação entre direitos do trabalhador e direitos sociais, ver Singer (2003).

6 Segundo o estudo do IBGE, o Brasil cresceu cerca de uma centena de vezes durante o século 20, porém chega aos dias de hoje como um dos países de pior distribuição de renda do mundo, tendo índices comparáveis a países africanos. Por fim, o país está entre as 15 potências industriais do mundo. Tal paradoxo pode ser também observado na relação entre índice de Gini, que mede o grau de concentração de renda de um país, e o consumo de produtos de luxo. Nessa relação, nosso índice histórico é fortemente concentra dor, o que explica a extrema pobreza versus o consumo em níveis e padrões europeu e estadunidense de uma elite constituída por milionários e pelas classes médias superiores (IBGE, 2007).

7 O Programa Gestão Pública e Cidadania (2007), da Fundação Getúlio Vargas (FGV/SP), que completou dez anos, notabilizou-se justamente por selecionar e armazenar experiências de gestões públicas, particularmente de pequenos municípios, voltadas à participação e à gestão pública promotora da cidadania - atinente, portanto, ao ethos da Constituição de 1988. Trata-se da demonstração, entre outros exemplos, de como é possível avançar na democratização, na participação popular e na cidadania.

8 É esta estrutura institucional que explica que, ao longo dos anos 1990, o Ministério da Saúde tenha conquistado a adesão dos governos estaduais e municipais ao SUS. Em maiode 2002,5.537 dos 5.560 municípios brasileiros-99,6\% do total - haviam assumido a gestão parcial ou integral dos serviços de saúde. Em 2000, os municípios brasileiros foram responsáveis, em média, por $89 \%$ do total da produção ambulatorial no Brasil, com um desvio padrão de 19\% (consideradas todas as categorias de provedores), e por $84 \%$ da rede ambulatorial, média esta acompanhada de desvio padrão decrescente. Isto é, a rede e a produção de serviços ambulatoriais se tornaram basicamente municipais, o que não era absolutamente a realidade da distribuição destes serviços no início dos anos 1990 (MARQUES; ARRETCHE, 2003). Esses resultados são, em boa medida, explicados pela capacidade de o Ministério da Saúde induzir as decisões dos governos municipais. Estes eram responsáveis por $9,6 \%$ do total do gasto consolidado em saúde em 1985, por35\% em 1996(MEDICI, 2002) e por 43\% em 2000 (FERREIRA, 2006). Pelo conceito de origem dos recursos, a participação dos municípios passou de 9,3\% em 1985 para28\% em 1996(MEDICI, 2002).

9 É claro que há todo um debate acerca da centralização promovida pelo SUS, que foge dos objetivos deste trabalho. De toda forma, é importante observar que os municípios são agentes de implementação, embora não de elaboração, das políticas de saúde no país.

\section{Francisco César Pinto da Fonseca}

Doutor em História Social pela Universidade de São Paulo (USP)

Mestre em Ciência Política pela Unicamp.

Professor de Ciência Política na Fundação Getúlio Vargas de São Paulo (FGV/SP)

Departamento de Fundamentos Sociais e Jurídicos da Administração

Rua Itapeva, 474, 7. andar

São Paulo - São Paulo

CEP: 01332-000 